\section{Ginecologia \\ GineCOMASTIA EM ADULTOS: APENAS ESTÉTICA?}

Paciente, sexo masculino, 33 anos, atendido no Serviço de Ginecologia do Hospital das Clínicas-FMUSP, com queixa de aumento do volume das mamas desde a adolescência e dor local de intensidade progressiva. Nega uso de medicações, hepatopatias, tireoidopatias, nefropatias. Nos antecedentes sexuais refere libido e orgasmo heterosexuais, mas história de infertilidade conjugal. Exame físico geral: altura I,78 m, peso $94,8 \mathrm{~kg}$, envergadura I,83 m. Na região do tórax apresenta ginecomastia bilateral com completo desenvolvimento mamário, na palpação revela parênquima normal, ausência de descarga papilar. Linfonodos axilares ou supra claviculares não palpáveis. $\bigcirc$ exame dos órgãos genitais apresenta aspecto masculino, com diminuição da pilificação e do volume testicular e pênis de pequenas proporções. Exames complementares: ultra-som de mamas que confirmou a presença de tecido mamário, ultrasom de testículos mostrando volume testicular diminuído, sem presença de tumoração. Dosagens hormonais, $\mathrm{FSH}, \mathrm{LH}$, sulfato deidroepiandrosterona, estradiol, normais para o sexo masculino, apenas testosterona ( || $5 \mathrm{ng} / \mathrm{dl})$ em nível baixo. $O$ espermograma mostrou azoospermia e o cariótipo leucocitário 47 XXY. O diagnóstico foi de síndrome de Klinefelter. Discutido o caso e analisado com o paciente, concluiu-se pelo tratamento cirúrgico da ginecomastia, maior problema e desconforto para o mesmo.

Este relato (síndrome de Klinefelter) é oportuno, pois permite caracterizar seus aspectos relevantes, oferecendo informações para profissionais da saúde de diferentes áreas, que pouco conhecem sobre esta síndrome, devido a sua baixa prevalência
( I/I 00.000 nascimentos). O objetivo foi orientar o diagnóstico e tratamento destes indivíduos, para proporcionar aos mesmos atendimento já na puberdade, possibilitando melhor prognóstico. As alterações endócrinas (hipogonadismo) que causam as manifestações clínicas, principalmente o hipogenitalismo e a ginecomastia, geralmente interferem no bem-estar destes indivíduos. A ginecomastia, mesmo quando transitória como no período puberal, sempre é motivo da apreensão e desconforto, merecendo atenção, pois estas mamas apresentam risco maior de neoplasia maligna que homens normais (20\%), estando indicado o tratamento cirúrgico da mesma. A partir da puberdade, outras neoplasias germinativas gonadais e extra-gonadais ocorrem em freqüência significativa, como podem manifestar-se ou acentuar-se distúrbios de comportamento. Por estas razões, os diferentes profissionais devem cogitar neste diagnóstico, e conduzir cada caso da melhor maneira, pesquisando a síndrome, eventuais neoplasias e distúrbios comportamentais, oferecendo a estes indivíduos melhor qualidade de vida através de assistência emocional, tratamento da ginecomastia e tratamento com androgênios.

Vicente Renato Bagnoli Angela Maggio da Fonseca Josef NACSON

Referências

I. Guidi HGC. Síndrome de Klinefelter. In: Pinotti,JÁ, Fonseca AM, Bagnoli VR, editores. Tratado de ginecologia. Condutas e rotinas da Disciplina de Ginecologia da Faculdade de Medicina da Universidade de São Paulo. Rio de Janeiro. Revinter; 2004. cap. 21 , p. $136-9$.

2. Evans DB, Cricholw RW. Carcinoma of the male breast and Klinefelter's syndrome. Is there an association. CA 1987;37(4):246-5I.

3. Dexeus FH, Logothetis CJ, Chong C, Sella A, Ogdem S. Genetic abnormalities in men with germ cell tumors. J Urol 1986; | 40(I):80-4.

4. Hershkovitz E, Leiberman E. Gynecomastia: a review. Endocrinologist 2002; $12(4): 321-32$. 